IZA DP No. 259

\title{
Poverty in the Russian Federation
}

\author{
Ada Ferrer-i-Carbonell
}

Bernard M.S. van Praag

February 2001 


\title{
Poverty in the Russian Federation
}

\author{
Ada Ferrer-i-Carbonell \\ University of Amsterdam \\ Bernard M.S. van Praag \\ University of Amsterdam and IZA, Bonn
}

Discussion Paper No. 259

February 2001

\author{
IZA \\ P.O. Box 7240 \\ D-53072 Bonn \\ Germany \\ Tel.: +49-228-3894-0 \\ Fax: +49-228-3894-210 \\ Email: iza@iza.org
}

This Discussion Paper is issued within the framework of IZA's research area Labor Markets in Transition. Any opinions expressed here are those of the author(s) and not those of the institute. Research disseminated by IZA may include views on policy, but the institute itself takes no institutional policy positions.

The Institute for the Study of Labor (IZA) in Bonn is a local and virtual international research center and a place of communication between science, politics and business. IZA is an independent, nonprofit limited liability company (Gesellschaft mit beschränkter Haftung) supported by the Deutsche Post AG. The center is associated with the University of Bonn and offers a stimulating research environment through its research networks, research support, and visitors and doctoral programs. IZA engages in (i) original and internationally competitive research in all fields of labor economics, (ii) development of policy concepts, and (iii) dissemination of research results and concepts to the interested public. The current research program deals with (1) mobility and flexibility of labor markets, (2) internationalization of labor markets and European integration, (3) the welfare state and labor markets, (4) labor markets in transition, (5) the future of work, (6) project evaluation and (7) general labor economics.

IZA Discussion Papers often represent preliminary work and are circulated to encourage discussion. Citation of such a paper should account for its provisional character. 
IZA Discussion Paper No. 259

February 2001

\section{ABSTRACT \\ Poverty in the Russian Federation*}

This paper is intended to shed light on the extent of poverty in the Russian Federation. We present estimates of poverty lines and poverty ratios derived from subjective questions used in a during data collection for a large household panel (RUSSET). We estimate poverty using a subjective approach, where the level of the poverty line is derived using the opinion of the individual, rich or poor, on poverty. This approach differs from the objective approach to poverty, which defines poverty according to the opinion of experts. Three subjective poverty lines are presented: one the Financial Satisfaction Poverty Line, two the Leyden Poverty Line, and three the Subjective Well-Being Poverty Line. The first two poverty lines are based on subjective questions regarding income and economic welfare while the last concept focuses on satisfaction with life as a whole. The results obtained are compared with each other and with results derived using 'objective' measures and official figures.

JEL Classification: C21, D31, D60, I32

Keywords: Poverty, subjective poverty, Leyden approach, well-being, financial satisfaction, Russian Federation.

Bernard M.S. van Praag

University of Amsterdam

Roetersstraat 11

1018 WB Amsterdam

The Netherlands

Tel.: +31 2052560 18/15

Fax: +31205256013

Email: bvpraag@fee.uva.nl.

\footnotetext{
* We are grateful to M.J. Ellman, K. Gërxhani, W. Saris, and an anonymous referee for useful comments. The usual disclaimers apply. We also like to thank M. Aldham-Breary for improving the English.
} 


\section{Introduction}

What is the true extent of poverty in the Russian Federation? This burning question is being investigated by a growing number of researchers (see, e.g., Frijters, 1999; Lokshin and Popkin, 1999; Popkin et al., 1996; Ravallion and Lokshin, 1999; Zohoori et al., 1998). The official estimates are $20.8 \%$ for 1997 and $23.8 \%$ for $1998^{1}$. These figures contrast with the impressions of journalists and other travelers in the Russian Federation who see a lot of conspicuous poverty on the street. It seems that there is a lot of confusion about this subject. We do not pretend to give a conclusive answer in this paper, our intention is to shed some light on the question using a large and informative household panel data set (RUSSET), which was started in 1993. Most of our colleagues will know of the existence of the RLMS-panel ${ }^{2}$, run by the University of North Carolina, the RUSSET panel data, organized by the University of Amsterdam³ ${ }^{3}$, is less wellknown, yet it is comparable in quality to the RLMS.

A question on the extent of poverty presupposes an operational definition of poverty, despite this, and for understandable reasons, there is not a generally accepted definition of poverty. In section 2 , we discuss a number of poverty concepts, which are applied to the RUSSET-data set. Poverty concepts are divided into objective and subjective measures. The difference between the two approaches is that in objective measures the poverty line in terms of income is defined by experts, while the poverty line in the subjective approach is derived from individual opinions of a population. It is doubtful whether monetary income is a good determinant of well-being in a society where there are a lot of transactions in kind. More fundamentally, the question may be posed: is money the primary determinant of life satisfaction? The obvious answer is no. It follows that we may distinguish between welfare and well-being, the latter being a wider concept, which includes variables that cannot be bought by money. Welfare Poverty is then a lack of, economic, welfare, while well-being poverty is tantamount to a lack of well-being or life satisfaction.

The main result of our study seems to be that depending on the definition used, poverty ratios vary. Poverty incidence depends on the measurement approach, and on the unit of analysis,

\footnotetext{
${ }^{1}$ These poverty figures are taken from the web page of The Russian Statistical Agency (GKS) http://www.gks.ru; under Handbook "Russia in Figures" (1999), Main Socio-Economic Indicators of the Living Standard of the Population.

${ }^{2}$ The Russian Longitudinal Monitoring Survey (RLMS) is supervised by the Carolina Population Center at the University of North Carolina at Chapel Hill. The first phase started in 1992 with around 6300 households. The second phase started in 1994 with almost 4000 households. The data has been collected a total of 8 times (4 for each phase). See, http://www.cpc.unc.edu/projects/rlms/rlms_home.html.

${ }^{3}$ The scientific responsibility for the survey lies with William Saris, University of Amsterdam. Fieldwork is carried out by the CESSI (Institute for Comparative Social Research, Moscow), coordinated by Dr. Anna Andreenkova. The survey is financed by the Dutch National Science Foundation (N W O).
} 
and the choice of equivalence scale (Atkinson, 1991). For example, a number of studies realized in Western countries show that subjective estimators tend to be lower than objective poverty ratios (see e.g. Van Praag, and Flik, 1992; and Van Praag, Flik, and Stam, 1997). Our study shows that this is not the case for the Russian Federation. Additionally, we find that both subjective and objective poverty ratios are much higher in the Russian Federation than in Western countries.

We discuss the different concepts and measurement of poverty in section 2 . We describe the data set which we use in section 3. We present our estimates in section 4 and in section 5, we discuss the results and draw some conclusions.

\section{Poverty: Definition and measurement}

\subsection{Definition of Poverty}

The first assumption on which any poverty analysis is based is interpersonal comparability of welfare or well-being. If the welfare of households $\mathrm{A}$ and $\mathrm{B}$, say $U_{A}$ and $U_{B}$, cannot be compared, we are unable to say whether A is equal to, or better or worse off than B. Welfare can be evaluated by individuals on a scale that may be numerical such as a 1 to 5 -scale or verbal, say a scale ranging from 'very dissatisfied' to 'very satisfied'. Interpersonal comparability means that individuals or households A and B are able to rank their situation on the same scale and that $U_{A}=1$ and $U_{B}=3$ implies that B is better off than A. Similarly $U_{A}=U_{B}$ implies that A and B enjoy the same level of welfare. The welfare concept we use is ordinal, i.e., if $U_{B}=2 U_{A}$ it does not imply that B is 'twice' as well-off as A, we do not know that. If we assume that evaluation is possible on a continuous scale, even if any real survey evaluation only gives the possibility for discrete answers on a 5- or 11-point scale, then it is possible to define a poverty threshold $U_{\min }$ such that, if $U_{A} \leq U_{\min }$, household A is poor and if $U_{A}>U_{\min }$ household A is not poor. The choice of that level $U_{\min }$ is purely arbitrary, it is a political decision. The lower the value of $U_{\min }$ that is chosen, the less people will be poor and those who are classified as poor will suffer more severe poverty.

If we want to recognize poverty, we need indicators of welfare. The most traditional welfare indicator is household income $y$. If welfare depends only on income, we have

$$
U=U(y)
$$


where $U$ is the ordinal welfare function. The function is always assumed to be monotonically increasing in income. If $U_{\min }$ is accepted to be the poverty threshold, this yields the poverty line $y_{\min }$ as the solution of

$$
U\left(y_{\min }\right)=U_{\min }
$$

We can see that, if the ordinal utility function is replaced by a monotonic transformation $\varphi($.$) , the threshold will become \hat{U}_{\min }=\varphi\left(U_{\min }\right)$ and

$$
\varphi\left(U\left(y_{\min }\right)\right)=\hat{U}_{\min }
$$

will yield the same poverty line as above. The simplest transformation is evidently $U(y)=y$. In this case, income is the welfare index. If we assume that income is the only welfare determinant, there is no reason to introduce the utility concept.

It may be, however, that welfare depends on more variables than just income. The most traditional variable is family (or household) size $f s$. Then we have

$$
U=U(y, f s)
$$

and consequently $y_{\min }$ follows from

$$
U\left(y_{\min }, f s\right)=U_{\min }
$$

with a solution for minimum income $y_{\min }(f s)$, which varies with family size.

Again we may replace $U$ by $\hat{U}=\varphi(U(y, f s)=\hat{U}(y, f s)$ where $\varphi($.$) is a monotonic function.$ Then $y_{\text {min }}(f s)$ is the solution of $\hat{U}(y, f s)=\varphi\left(U_{\text {min }}\right)=\hat{U}_{\text {min }}$. Hence a poverty line does not depend on which transformation is used.

Next, we need a description of the indifference curves

$$
U(y, f s)=C
$$

where $\mathrm{C}$ stands for a constant. Using the indifference curve we can obtain family equivalence $\underline{\text { ratios, }}$ which are derived from the equation: 


$$
U(y+\Delta y, f s+\Delta f s)=U(y, f s)
$$

The solution of this equation with respect to $\Delta y$ gives an answer to the question of how much additional income, $\Delta y$ is needed to compensate an increase of $f s$ by $\Delta f s$, e.g. from $f s=2$ to $f s=$ 3.

This is presented graphically in figure I. In figure 1 we depict three indifference curves. The poverty line in the middle is the boundary line between well-off and poor.

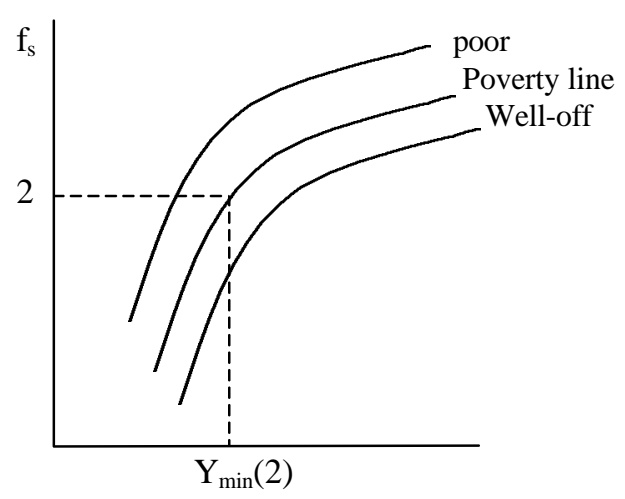

Figure 1 Indifference curves income-family size

The upper and lower curves are arbitrary indifference curves in the 'poor' and 'well-off' region respectively. A poverty line is realistic if $y_{\min }(f s)$ corresponds to a boundary situation between poor and well-off as felt by the individual/household for their position. Likewise the shape of the indifference curve is realistic if people with different household situations on the curve feel they are in the same boundary position, i.e., the welfare of all the different households equal $U_{\min }$. One of the questions we shall consider in this paper is whether the various poverty lines are realistic in the sense given above. If $U_{\min }$ is not chosen realistically, for instance it is too low, then a number of people will feel poor, although they are 'officially' not considered to be poor.

\subsection{Measurement of Poverty}

Let us now list the poverty measures we will apply and explain how they fit into the framework given above. Two kinds of approaches are presented, namely objective and subjective poverty. 


\subsubsection{Objective approaches}

We distinguish two objective approaches, viz. an absolute and a relative version.

\section{Minimum income approach (absolute approach)}

This is a well-known traditional approach. A minimum income level $y_{\min }$ is fixed by experts. As a rule this level depends on the family size. This relationship with family size is also fixed. For instance, according to the 'Oxford scale' the first adult counts for 1 , other adults for 0.7 and children younger than fifteen carry a weight of 0.5 . For a reference household, say of two adults and two children, the total weight is then $1+0.7+0.5+0.5=2.7$. The Oxford scale is constructed on the basis of some intuitive ideas about economies of scale.

In most cases, the level $y_{\min }$ is determined as the income which would allow a reference household to live at a minimum subsistence level. The minimum income for a household with a weight of 2 is then found to be $2 / 2.7$ times the minimum income of the reference household.

The official poverty line for Russia is constructed on the basis of Popkin et al. (1996). Their method consists of two steps. One, a reasonable subsistence level food basket is determined for a two-adults household in the lower income class. Then, the average food share for lower income classes in 1994 was estimated to be $75 \%$ of total expenditure. Hence a minimum income level was set at $1 / 0.75=1.33$ times the food cost for the minimum basket. This level was defined as the poverty line for a two-adult household.

Two, a family equivalence scale system is developed, which is based on the Rothbarth method (Rothbarth, 1943; Deaton and Muellbauer, 1986). The basis of this method is the idea that consumption per adult of certain "adult" consumption goods should be constant over households of varying size if the households enjoy equivalent income.

It is obvious that the choice of what makes a subsistence level food basket is rather arbitrary. Given the fact that the food share decreases with rising income (Engel's law) and that in Western countries a food share of $1 / 3$ or $1 / 2$ is usually linked with lower incomes (see Orshansky, 1965 ) it follows that the poverty line in Russia is extremely low and that the blow-up factor is extremely small. The Rothbarth method is also debatable.

\section{The objective relative approach}

The relative approach is a somewhat more sophisticated approach. In this case, the poverty line is fixed at a specific position in the income distribution of the relevant population. It may be the $20 \%$ quantile or $50 \%$ of median or mean income in the population (see, e.g., Fuchs, 1967). In order to correct for differences in family size the incomes are first 'standardized' according to 
some equivalence scale, e.g., the Oxford-scale or the scale suggested by Popkins et al. (1996) following the Rothbarth method. In this case, the relevant underlying utility functions are $U=F(y)$ where $F($.$) stands for the standardized income distribution function, and y_{\text {med }}$ stands for the standardized median income.

In the $20 \%$ quantile case, the poverty line is derived from

$$
F\left(y_{\min }\right)=0.2
$$

It is obvious that the poverty ratio is constant at $20 \%$. Only the composition of the poor population may change.

In the $50 \%$ median approach, the poverty line $y_{\text {min }}$ is defined by

$$
y_{\min } / y_{\text {med }}=0.5
$$

In this latter approach, the composition and the size of the poor population may change. The problem with this objective relative approach is its behavior if all incomes grow at the same rate. E.g., if all incomes are multiplied by two, intuition would say that poverty is reduced. According to these measures, however, it would stay constant. A similar problem exists if all prices are inflated by a factor 2 . The real income distribution would change, but not the nominal one.

\subsubsection{Subjective approach}

The subjective approach may be characterized as follows. One, derive from surveys among individuals which income level $y_{\text {min }}$ corresponds to poverty. Two, derive how $y_{\text {min }}(f s)$ varies with $f s$ or, if $y_{\min }$ is assumed to depend on age and other factors $x$, how $y_{\min }$ depends on these other factors $x$. Here, we will assume that $y_{\min }$ depends only on family size $(f s)$, which includes all members currently living in the household. Future work will extend the analysis to other more complex specifications that will take into consideration family composition, e.g., the number of children and the number of adults. The main objective of the current paper is, however, methodological and, thus, we simplify the analysis by including only $f s$. 
There are several variants of the approach, depending on variously worded question modules. This subjective approach is the core method of this paper.

\section{The Financial Satisfaction Poverty Line (FSPL)}

The FSPL is based on the following question:

" How satisfied are you with the financial situation of your family?

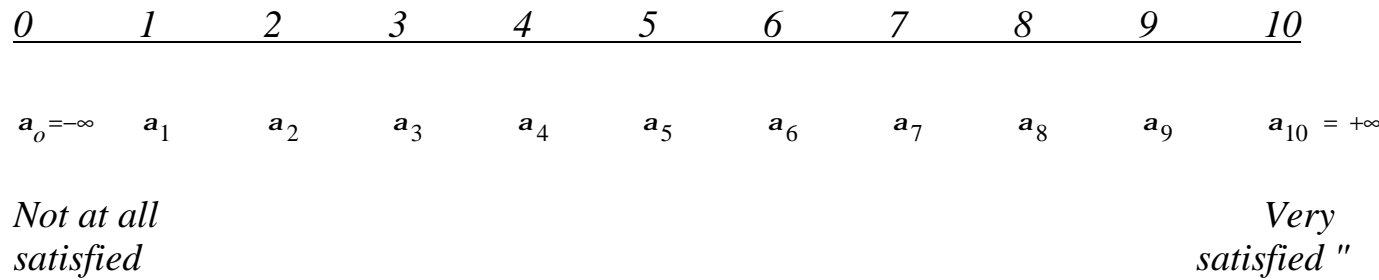

Let us denote the answer between zero and ten as SFS (Subjective Financial Satisfaction). Then SFS will be a function of current income $y_{c}$, family size $f s$, and probably other variables such as age. Simplifying, we have,

$$
S F S=U\left(y_{c}, f s\right)
$$

Let us assume that poverty is defined by the situation of those who evaluate their situation as 3 . Then $y_{\min }(f s)$ is the solution of

$$
U\left(y_{\text {min }}(f s), f s\right)=3
$$

If SFS is monotonically transformed by a function $\varphi($.$) , such that the equation (10) becomes$

$$
\gamma_{0}+\gamma_{1} \ln y_{c}+\gamma_{2} \ln f_{s}=\varphi(S F S)
$$

then the solution will be

$$
\ln y_{\min }=\frac{1}{\gamma_{1}}\left[\varphi(3)-\gamma_{0}-\gamma_{2} \ln f_{s}\right]
$$


The solution for $\varphi$ which suggests itself is based on the Ordered Probit Estimation method. We assume

$$
P[n<S F S \leq n+1]=P\left[\alpha_{n} \prec \gamma_{0}+\gamma_{1} \ln y_{c}+\gamma_{2} \ln f S+\varepsilon \leq \alpha_{n+1}\right]
$$

where $n=0, \ldots, 10$ with $\alpha_{0}=-\infty, \alpha_{10}=+\infty$. The coefficients $\gamma_{0}, \gamma_{1}, \gamma_{2}$ and $\alpha_{1}, \ldots, \alpha_{9}$ are estimated by Ordered Probit, based on the usual assumptions. The error term is $\mathrm{N}(0,1)$ distributed. Notice that we are forced to specify a concrete level as the poverty line, i.e. 3 . We specify level 3 , in the transformation version, $\alpha_{4}$, as the poverty line level, hence.

$$
\ln y_{\min }=\frac{1}{\gamma_{1}}\left[\alpha_{4}-\gamma_{o}-\gamma_{2} \ln f_{S}\right]
$$

In other words, applying to equation (15) the coefficients that have been estimated in equation (14), we can calculate the Financial Satisfaction Poverty Line at level 3. These results are presented in section 4 .

\section{The Leyden Poverty Line (LPL)}

The LPL (see Goedhart et al., 1977) was derived by a research group working at the University of Leyden in the seventies and eighties (see, e.g., Van Praag and Frijters, 1999). The basic question module is the Income Evaluation Question (IEQ), which runs as follows.

"Assuming prices to be constant, what monthly income (net of taxes) would you consider for your household as:

very bad.

bad.

not bad not good.

good......

very good
Thousands of Rubles per month

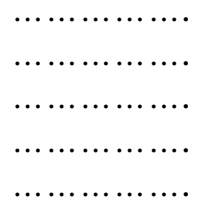


The answers are denoted by $c_{1}, \ldots, c_{5}$ respectively. This question is slightly more sophisticated than the SFS question. Firstly, no evaluation of own income is required and secondly we ask for five different levels, corresponding to the different levels of satisfaction.

The advantages of the IEQ compared to the SFS question are two fold. One, respondents are less inclined to exaggerate their own dissatisfaction with their own circumstances. In direct questions such as the SFS, respondents are likely to reduce the satisfaction shown with their own situation as a strategic reaction.

Two, the IEQ asks for five levels, not one, evenly spread over the satisfaction scale. This helps to calibrate the answers. Moreover, having five points gives more information about the relation between income and income satisfaction than having just one answer, related to own current income. The obvious disadvantage of the IEQ is that it asks for five levels instead of one, which requires more effort and thinking from the respondent.

It has been shown elsewhere (van Praag, 1991) that the verbal levels may be translated into equally spaced points on the (0,10)-axis, yielding $1,3,5,7,9$ respectively. It follows that we can estimate for each respondent his or her own individual welfare function $U(y)$. Taking for $U($.$) the long-standing lognormal distribution function \Lambda(y ; \mu, \sigma)$, we find the individual's evaluation of an income level $y$ to be

$$
U(y)=\Lambda(y ; \mu, \sigma)
$$

The parameters $\mu$ and $\sigma$ are estimated for each individual by $\hat{\mu}_{i}=\frac{1}{5} \sum_{i=1}^{i=5} \ln c_{i j}$ and $\sigma_{i}^{2}=\frac{1}{4} \sum_{i=1}^{i=5}\left(\ln c_{i j}-\mu_{i}\right)^{2}$ respectively. It has been empirically established that $\mu$ is an individually varying parameter, which depends notably on own current income $y_{c}$ and $f_{S}$. More specifically, for many countries the relationship

$$
\mu=\beta_{0}+\beta_{1} \ln y_{c}+\beta_{2} \ln f_{s}
$$

has been found (see, e.g., Van Praag, 1971; Van Praag and Kapteyn, 1973; Hagenaars, 1986 ). The parameter $\sigma$ has not been "explained" very well, and it is mostly taken to be constant among individuals. 
For the lognormal distribution we have

$$
\Lambda(y ; \mu, \sigma)=N\left(\frac{\ln y-\mu}{\sigma} ; 0,1\right)
$$

In fact, the lognormal distribution is just one ordinal utility version. Again, we may apply any monotonic transformation and an attractive one is that which yields us

$$
U^{*}(y)=\ln y-\mu
$$

taking $\sigma$ to be constant. Then the monotonic transformation used is the inverse of the normal distribution function $U^{*}=\sigma \cdot N^{-1}(U ; 0,1)$, since

$$
U^{*}(y)=\sigma \cdot N^{-1}\left[N\left(\frac{\ln y-\mu}{\sigma} ; 0,1\right)\right]
$$

As $\mu$ depends on current income $y_{c}$, the evaluation of current income is

$$
U^{*}\left(y_{c}\right)=\ln y_{c}-\beta_{0}-\beta_{1} \ln y_{c}-\beta_{2} \ln f s=\left(1-\beta_{1}\right) \ln y_{c}-\beta_{0}-\beta_{2} \ln f s
$$

The corresponding $U$-value is

$$
U\left(y_{c}\right)=N\left[\frac{\left(1-\beta_{1}\right) \ln y_{c}-\beta_{0}-\beta_{2} \ln f_{s}}{\sigma}\right]
$$

Now we set $y_{\min }$ at a level which corresponds to the label 'bad' in the IEQ, i.e., we specify the poverty line by

$$
U\left(y_{\min }\right)=0.4
$$

or equivalently 


$$
U^{*}\left(y_{\min }\right)=\sigma . N^{-1}(0.4)
$$

or

$$
\left(1-\beta_{1}\right) \ln y_{\min }-\beta_{0}-\beta_{2} \ln f s=u_{0.4}
$$

yielding

$$
\ln y_{\min }=\frac{u_{0.4}+\beta_{0}+\beta_{2} \ln f s}{1-\beta_{1}}
$$

The poverty level is determined by the choice of 0.4 or $u_{0.4}$, the normal quantile corresponding to an accumulative chance of 0.4. Summarizing, if we apply to equation (26) the coefficients estimated in equation (17), we find the Leyden Poverty Line for level 4. These results are presented in section 4. Note that if the SFS and the LPL measures stand for the same concept we should find that $-\frac{\gamma_{2}}{\gamma_{1}}$ is approximately equal to $\frac{\beta_{2}}{1-\beta_{1}}$. The income coefficient sign is expected to be positive for both, SFS and IEQ, whereas the family coefficient sign is expected to have the opposite sign. As family size rises, while income stays constant, the Subjective Financial Satisfaction will deteriorate, i.e. negative coefficient. Similarly, increases in family size augment the income that households consider to be "very bad",.., "very good" (positive coefficient). Frijters (1999) using the first waves of the RUSSET panel and the Erasmus Houdehold Survey presents poverty estimates using this method for Russia in 1991, 1993, 1994, and 1995. Thus, his estimates were performed for an earlier period.

\section{Subjective well-being Poverty Line (SWB)}

The previous two measures are based on question modules which focus on 'financial' or 'economic' aspects. A question which attempts to include all aspects of life is a question originally derived by Cantril (1965). The Cantril question runs as follow: 
"How satisfied are you with your life as a whole?

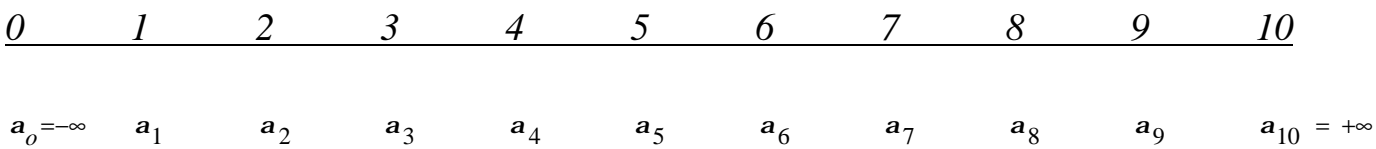

Not at all

satisfied

Very

satisfied"

The answer to this question is often termed subjective well-being (SWB). It is obvious that SWB will be determined by many more variables than income and family size alone. Nevertheless, given that the other variables, such as age, gender, being single and education, are not considered to be politically relevant, we assume a more simple specification. Let us assume that we estimate the relationship

$$
S W B=f(\ln y, \ln f s)
$$

Following equation (27), in a similar manner to the way SFS was estimated, we find

$$
\ln y_{\min }=\frac{1}{\delta_{1}}\left[\hat{\alpha}_{3}-\delta_{2} \ln f_{s}\right]
$$

Actually, a better estimate of the equation is arrived at following Plug and Van Praag (1995) by including a squared $(\ln f s)^{2}$ and an interaction term between $f s$ and $y$, i.e. taking the product $\left(\ln y_{c} \ln f s\right)$. This yields additional effects $\delta_{3}$ and $\delta_{4}$ in the Ordered Probit equation

$$
\delta_{0}+\delta_{1} \ln y_{c}+\delta_{2} \ln f s+\delta_{3} \ln f s \ln y+\delta_{4}(\ln f s)^{2}=\varphi(S W B)
$$

The rationale for including the quadratic form is that it seems probable that SWB does not monotonically increase or fall with family size $f s$. A finite optimal family size becomes possible by including the square of $f s$. Second, we may assume that that optimum $f s$ depends on the financial situation. This is realized by adding the interaction term.

Then we get for the SWB-poverty line: 


$$
\ln y_{\text {min }}=\frac{1}{\delta_{1}+\delta_{3} \ln f s}\left[\hat{\alpha}_{5}-\delta_{2} \ln f s-\delta_{4}(\ln f s)^{2}\right]
$$

Next, we can introduce to equation (30) the coefficients estimated in equation (29), to get a Subjective Well-Being Poverty Line for a level of satisfaction equal to 4 . These results are presented in section 4.

The Cantril question has already been considered among others by Blanchflower and Oswald (2000), Clark and Oswald (1994), Di Tella et al. (2000), Frey and Stutzer (1999), Frijters (1999), Frijters and van Praag (1998), Oswald (1997), Plug (1997), van Praag and Plug (1995a, 1995b), and van Praag et al. (2000).

\section{Description of the Data}

The RUSSET panel data has been used in this study. The design and data collection of the RUSSET panel have been described in detail in the paper of Saris and Andreenkova (2001) in this issue. Saris and Andreenkova state that two samples were drawn, for our study we used the new sample, which consists of two waves, namely wave 5 (1997) and Wave 6 (1998). The initial Wave came from a national probability sample of the Russian population of 18 years and older. It consisted of 3700 households, from which only 2000 remained in Wave 4 (1997). The new sample was initiated in 1997 with 2233 households (Wave 5). In Wave 6 (1998) the number of households was 1510 .We use weight variables constructed on the base of gender, age, and region for the analysis.

In this study we used the variables family size and family income. Family size refers to the number of persons that live in the household. Therefore, it does not include children or family members that live apart. The question of family income is rather intricate in the Russian Federation. It is well known that the sources of income for Russians are diverse and often come from the informal economy. The question used to obtain the family income variable runs as follow

"What is your total family monthly income, including pensions, aliments and so on for the last month after taxes?"

This type of question is frequently used in household surveys which do not focus especially on income assessment. In Russia this type of question is used by major opinion agencies such as VSIOM. It is a straightforward question which can be posed to many respondents in oral or mail 
surveys. Relatively few people refused to answer on this type of question (13\% in 1997 and 1998).

The household income concept is clearly an ambiguous concept, which is hard to materialize, as every income statistician knows. The Russian Statistical Office (GKS) and the RLMS aim for a much more refined income concept, also covering charity, gifts, income in kind, such as fruit and vegetables from own garden, subsidies, etc. It is obvious that this household income concept is more refined than the one we have at hand, but it is also obvious that its operationalization takes much more time and effort for the respondent, that it will cause higher non-response rates, and finally that the margin for uncertainty increases, because the valuing of ones own production or a subsidy on housing, due to leasing for a low rent, gives ample room for subjectivity for the evaluator. Both concepts have their strong and weak points.

Actually, each Russian household has so to speak two incomes, say $y^{(A)}$, assessed according to the definition we use, and $y^{(B)}$ according to the GKS and RLMS definition. Obviously $y^{(A)} \leq y^{(B)}$. It follows that there are also two poverty lines, say $y_{\min }^{(A)}$ and $y_{\min }^{(B)}$, referring to the alternative income concepts. When we apply the poverty line definition based on $y_{\min }^{(B)}$ to our sample, where income is described as $y^{(A)}$, the poverty ratio should be higher than when applying the same poverty line $\left(y_{\min }^{(B)}\right)$ to a sample with income defined as $y^{(B)}$. Therefore, even when using the same official minimum income $\left(y_{\text {min }}^{(B)}\right)$, we get a higher percentage of poverty incidence in our sample than that given in the official statistics, figure 2 makes this clear.

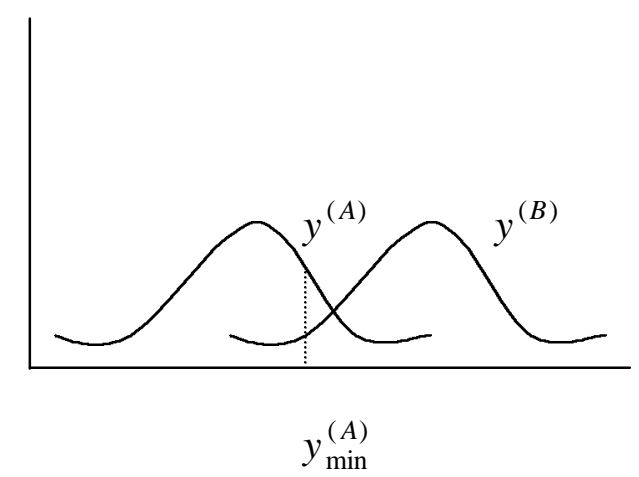

Figure 2 Income definition and poverty line 


\section{Estimation Results}

In this section, we present the estimates of the equations (12), (17), and (29), and the resulting poverty lines and poverty ratios, equations (15), (26), and (30). The results are based on the RUSSET data set. For completeness, we add other comparable poverty figures drawn from the Russian Statistical Office (GKS), from Popkins et al. (1996), and from the "relative" half-median and half-mean approaches.

Although the data were derived from a longitudinal survey, we use the consecutive waves as separate cross-sections. The reason for this is that the usual poverty estimates are based on cross-sections, from year to year.

The estimation results for the SFS (equation 12), for the $\mu$ of the IEQ equation (17), and for the SWB (equation 29) are presented in table 1. The estimation method used for equations (12) and (29) is Ordered Probit, where the dependent variable takes the values $0,1 \ldots, 10$; equation (17) was estimated using OLS. 
Table 1: Estimation results for wave 5 (1997) and 6 (1998)*

\begin{tabular}{|c|c|c|c|c|c|c|}
\hline & \multicolumn{3}{|c|}{ Wave 5: 1997} & \multicolumn{3}{|c|}{ Wave 6: 1998} \\
\hline Variable & SFS & $\operatorname{IEQ}(\mu)$ & SWB & SFS & $\operatorname{IEQ}(\mu)$ & SWB \\
\hline $\ln y_{c}$ & $\begin{array}{c}0.722 \\
(0.039)\end{array}$ & $\begin{array}{c}0.370 \\
(0.018)\end{array}$ & $\begin{array}{c}0.503 \\
(0.080)\end{array}$ & $\begin{array}{c}0.570 \\
(0.044)\end{array}$ & $\begin{array}{c}0.365 \\
(0.020)\end{array}$ & $\begin{array}{c}0.352 \\
(0.091)\end{array}$ \\
\hline $\ln f_{s}$ & $\begin{array}{l}-0.522 \\
(0.061)\end{array}$ & $\begin{array}{c}0.422 \\
(0.032)\end{array}$ & $\begin{array}{c}1.164 \\
(0.427)\end{array}$ & $\begin{array}{l}-0.328 \\
(0.066)\end{array}$ & $\begin{array}{c}0.392 \\
(0.033)\end{array}$ & $\begin{array}{c}0.579 \\
(0.470)\end{array}$ \\
\hline$(\ln f s)^{2}$ & & & $\begin{array}{c}0.021 \\
(0.120)\end{array}$ & & & $\begin{array}{c}-0.085 \\
(0.114)\end{array}$ \\
\hline $\ln y_{c} \ln f s$ & & & $\begin{array}{l}-0.167 \\
(0.074)\end{array}$ & & & $\begin{array}{l}-0.050 \\
(0.078)\end{array}$ \\
\hline $\begin{array}{l}\text { Adj-R }^{2} \text { (IEQ) } \\
\text { Pseudo R } \\
\text { (SFS, SWB) } \\
\end{array}$ & 0.210 & 0.400 & 0.185 & 0.205 & 0.403 & 0.186 \\
\hline Wave 5 & & $\begin{array}{c}-\gamma_{2} / \gamma_{1} \\
0.724\end{array}$ & & & $\begin{array}{c}\beta_{2} /\left(1-\beta_{1}\right) \\
0.670\end{array}$ & \\
\hline Wave 6 & & 0.575 & & & 0.618 & \\
\hline $\begin{array}{l}\text { Delta method used } \\
\text { calculate the stand } \\
\text { difference betweer } \\
\text { ratios }{ }^{4}\end{array}$ & $\begin{array}{l}\text { ized } \\
\text { e two }\end{array}$ & 0.574 & & & -0.251 & \\
\hline
\end{tabular}

* The standard error is given in parenthesis.

When we asses the variances of the two ratios $-\gamma_{2} / \gamma_{1}$ and $\beta_{2} / 1-\beta_{1}$ using the delta-method, we find that the standardized differences between both ratios are 0.574 and -0.251 for wave 5 and 6 respectively. It implies that these differences are statistically non-significant. This indicates that the IEQ and the SFS question measure similar concepts. The results of the regression of $\mu$ show that family income and family size are positive and significant. This implies that $\mu$ depends strongly on family size and family income. In other words, if family size increases, the income that a household would consider "very bad", ..., "very good" increases. A noticeable difference 
between these results and the ones found in other European countries, is the high coefficient for $\ln f s$. Usually, the family size coefficient is found to be somewhere between 0.075 , Denmark, and 0.169, Ireland, (see van Praag et al., 1982). The larger family size coefficients found in the Russian Federation may be due to the fact that family protection policies are much less liberal in Russia than in Western countries. Therefore, the cost of an additional child is higher in Russia than in Western countries. The significant coefficient forln $y_{c}$ indicates an effect of own income on the evaluation schedule of income. This has been called the preference drift (Van Praag, 1971). This means that own income is an anchor point. Psychologists have called this phenomenon the hedonic treadmill (Brickman and Campbell, 1971). In contrast to the family size coefficient, the coefficient for $\ln y_{c}$ is found to be rather low when compared to the European average. This is probably caused by the effect of Russian income varying a lot over time, both in real and nominal term. Moreover, there is more income in kind. It follows that own income is less stable as an anchor-point than in Western countries. The SFS estimates are consistent with the IEQ and indicate that individuals with higher income report a larger SFS value, and that individuals with a bigger family size experience a lower SFS. The SWB question gives a more complex picture. One, for wave 6 , coefficients involving family size are non-significant, and in wave 5 the squared of family size is also not significant. Two, family size is incorporated in the equation as squared and as an intercept term with family income. Three, respondents with a higher income also report higher SWB. The income coefficient for SWB is in both waves very significant and considerably high. These results imply that income is an important factor for subjective well-being in the Russian Federation. Usually it is found that the correlation between income and life satisfaction is higher for the less developed countries, see, for an overview, Argyle, (1999).

An alternative measure of poverty can be derived from counting how many respondents consider their household situation to be under a level 3,4 , or 5 . Thus, poverty incidence is measured as the percentage of individuals responding to the SFS and SWB questions with values below a specific level. This analysis is presented in table 2 . For comparative reasons, table 2 also shows the results obtained for Germany when using the German Socio-Economic Panel (GSOEP) data set ${ }^{5}$. Table 2 exemplifies that the percentage of people who feel dissatisfied with both their

$4\left(\frac{\left(-\gamma_{2} / \gamma_{1}\right)-\left(\beta_{2} / 1-\beta_{1}\right)}{\sqrt{\sigma_{-\gamma_{2} / \gamma_{1}}^{2}+\sigma_{\beta_{2}}^{2} / 1-\beta_{1}}}\right)$

${ }^{5}$ The German Socio-Economic Panel (GSOEP) is a longitudinal panel of households that started in 1984 in the West and in 1990 in the East . The GSOEP is described in Wagner et al. (1993). The GSOEP is 
financial and well-being situation is rather large, especially when compared to Western countries. Table 2 also shows that the dissatisfaction levels of Russians are higher for the financial situation than for the well-being.

Table 2: Frequencies for the SFS and SWB

\begin{tabular}{|c|c|c|c|c|}
\hline & \multicolumn{2}{|c|}{ SFS } & \multicolumn{2}{|c|}{ SWB } \\
\hline $\begin{array}{l}\text { Answers for } \\
\text { RUSSET }\end{array}$ & $\begin{array}{c}\text { Wave 5: } \\
1997\end{array}$ & $\begin{array}{c}\text { Wave 6: } \\
1998\end{array}$ & $\begin{array}{c}\text { Wave 5: } \\
1997\end{array}$ & $\begin{array}{c}\text { Wave 6: } \\
1998\end{array}$ \\
\hline$\%$ Below 3 & $57.8 \%$ & $67.8 \%$ & $23.0 \%$ & $40.7 \%$ \\
\hline$\%$ Below 4 & $67.6 \%$ & $77.6 \%$ & $32.5 \%$ & $51.2 \%$ \\
\hline$\%$ Below 5 & $82.9 \%$ & $89.3 \%$ & $57.6 \%$ & $72.5 \%$ \\
\hline \multirow[t]{2}{*}{ Answers for GSOEP } & \multicolumn{2}{|c|}{ West Germany * 1997} & \multicolumn{2}{|c|}{ East Germany *, 1997} \\
\hline & SFS & SWB & SFS & SWB \\
\hline$\%$ Below 3 & $5.8 \%$ & $4.4 \%$ & $6.4 \%$ & $5.6 \%$ \\
\hline$\%$ Below 4 & $11.2 \%$ & $8.5 \%$ & $12.6 \%$ & $10.5 \%$ \\
\hline$\%$ Below 5 & $24.2 \%$ & $20.4 \%$ & $32 \%$ & $29.9 \%$ \\
\hline
\end{tabular}

A comparable question to the SWB or SFS-question has been analyzed by Ravallion and Lokshin (1999). They call it the 'Economic Ladder Question' (ELQ) which runs as follows:

"Please imagine a 9-step ladder where on the bottom, the first step, stand the poorest people, and on the highest step, the ninth, stand the rich. On which step are you today?"

The ELQ has been posed in the roughly comparable RLMS (Russian Longitudinal Monitoring Survey) data set. Ravallion and Lokshin suggest that their question represents a broader concept of poverty, than only financial poverty. We are not so sure about this interpretation, as 'poor' is mostly interpreted in literature and ordinary language as meaning financial poverty. However, similar figures follow from their paper. Their results show that in 1996, 31.5\% of adults responded to the ELQ with 1 or 2, 54.28\% answered 3 or less, $74.47 \%$ reported 4 or less, and 94.24\% gave a 5 or less to the ELQ (Ravallion and Lokshin, 1999). In 1998, these results were respectively $37.27 \%, 61.28 \%, 81.12 \%$, and 96.86\% (Lokshin and Ravallion, 2000). Lokshin and Ravallion (2000) found that individuals' welfare decreased from 1996 to 1998. This finding is

sponsored by the Deutsche Forschungsgemeinschaft and organized by the German Institute for Economic Research (Berlin), and the Center for Demography and Economics of Aging (Syracuse University). We are grateful to these institutes and the project director Dr. G. Wagner for making this data set available. 
consistent with our results and with the economic deterioration of the Russian Federation after the crisis in August 98.

Next, applying the results given in table 1, we can find the income poverty lines and corresponding poverty ratios for 1997 and 1998. The poverty lines are presented in table 3 and the poverty ratios in table 4 . The poverty lines presented in table 3 are the following. One, two relative objective measures are presented, namely the half-mean and half-median. For that, we used the family size correction given by Popkin et al. (1996, table 10), which is based on the 'adult good' per capita method, in which the 'adult good' is adult male protein intake. Table 3 indicates that the poverty lines for these measures are the lowest and thus will lead to the lowest poverty ratio (Table 4). Two, two economic welfare poverty subjective measures are presented, namely the LPL and the SFSPL. These were calculated using equation (15) and (26) as described in section 2.2.2. Three, we present a well-being poverty subjective measure calculated using equation (30) in section 2.2.2. Four, table 4 the poverty line derived, using own calculations, in the style of Popkins et al. (1996) is presented in table 4. Popkins et al. (1996) only offers the poverty lines until April 1993. Using the inflation rate provided by the GKS, we have converted their poverty lines to November 1997 and November 1998, when wave 5 and wave 6 of the RUSSET were conducted. The official poverty line offered by the $\mathrm{GKS}^{6}$ is only available as an average per capita. Applying the scale used by Popkin et al. (1996, Table 10), we can derive the poverty line for various family sizes.

\section{[INSERT TABLE 3 ABOUT HERE]}

Using the poverty lines (table 3), we can calculate the percentage of our sample living in poverty. The percentage of individuals in poverty is shown in table 4, where all individuals living in a poor household are considered to be poor. The equivalence scales in Popkins et al. (1996, table 10) are used for the half-mean, the half-median, and the Official GKS poverty lines. For the other measures, the equivalence scales used follow from table 3.

\section{[INSERT TABLE 4 ABOUT HERE]}

Table 4 indicates that: one, the relative measures of poverty lead to a very low poverty incidence and seem rather un-realistic. Two, well-being poverty is much lower than welfare, or economic, poverty. Three, the objective absolute measures of welfare poverty, Popkins and GKS, 
and the subjective measures, SFS and IEQ, give different results depending on the years, the satisfaction levels chosen and on the questions used to evaluate poverty. The satisfaction level chosen for the subjective poverty measures can be varied to obtain the same level of poverty as that for the objective measures. For example, when comparing the SFS poverty line with the Popkins poverty line we see similar results for 1998. Therefore, we can say that in 1998, the Popkins measure, objective poverty, gives similar poverty percentages as the Subjective Financial Satisfaction poverty line for a level of satisfaction equal to 3. For 1997, the SFS poverty line for level 3 gives a lower percentage of poverty than the Popkins measure, objective poverty. We could, however, choose a level of financial satisfaction other than 3. For example, in 1997 the SFS Poverty incidence at a level of satisfaction equal to 4 is $87.4 \%$, which is similar to the Popkins poverty incidence of 80.7\%. Four, the poverty ratios have increased from 1997 to 1998. This is in accordance with the worsening situation that the Russian Federation has experienced since August 1998. Similar results are found by Lokshin and Ravallion (2000), who using the RSLM panel, found a deterioration of welfare measured with both objective and subjective measures after August 1998.

The poverty ratio for the whole Russian Federation using the official poverty line is given by the GKS as $20.8 \%$ (1997) and 23.8\% (1998). Those percentages are much lower than in our case, $52.8 \%$ and $64 \%$ respectively, where we apply the same poverty line to the RUSSET sample, i.e. 411.2 rubles per month in 1997 and 493.9 in 1998. Similarly, Popkins et al., (1996), whose analysis forms the basis for the official poverty ratios (GKS), find lower percentages of poverty incidence when applying their poverty line on the RLMS sample. The RLMS poverty percentage is 55\% for Round VIII (October 1998 to February 1999) (http://www.cpc.unc.edu/projects/rlms/rlms_home.html). The reason for this has already been discussed extensively in section 3. As argued there, the RUSSET uses a definition of income which differs from the GKS and RLSM definition. In other words, the income definition used in the RUSSET sample gives much lower incomes. The income distribution differences for the three cases, i.e. GKS, RLMS, and RUSSET are presented in table 5.

\footnotetext{
${ }^{6}$ See www.gks.ru.
} 
Table 5: Monthly Income

\begin{tabular}{|c|c|c|c|c|c|}
\hline \multirow[t]{2}{*}{ Description } & \multicolumn{2}{|c|}{ RUSSET } & \multirow{2}{*}{$\begin{array}{c}\text { RLMS } \\
\text { Oct-98 to } \\
\text { Feb-99 }\end{array}$} & \multicolumn{2}{|c|}{ GKS $^{*}$} \\
\hline & $\begin{array}{l}\text { Wave } 5 \\
\text { Nov. } 1997\end{array}$ & $\begin{array}{l}\text { Wave } 6 \\
\text { Nov. } 1998\end{array}$ & & 1997 & 1998 \\
\hline $\begin{array}{l}\text { Mean Income per capita } \\
\text { In Nominal Rubles }\end{array}$ & 585 & 573 & n.a. & 934.7 & 968.6 \\
\hline $\begin{array}{l}\text { Mean Household Income } \\
\text { In Nominal Rubles }\end{array}$ & 1227 & 1232 & 1837 & n.a. & n.a. \\
\hline
\end{tabular}

\begin{tabular}{cccccc}
\hline \multicolumn{4}{c}{ RUSSET $^{* * *}$} & RLMS & \multicolumn{3}{c}{ GKS $^{* *}$} \\
\hline Wave 5 & Oct-98 to & Oct-98 to & 1997 & 1998 \\
Nov. 1997 & Feb-99 & Feb-99 & &
\end{tabular}

Income Distribution

Average per capita

\begin{tabular}{llllll}
$<401$ & $62.7 \%$ & $64.4 \%$ & n.a. & $19.7 \%$ & $15.1 \%$ \\
$<601$ & $79.4 \%$ & $81.5 \%$ & n.a. & $39.1 \%$ & $34.1 \%$ \\
$<801$ & $89.9 \%$ & $91.6 \%$ & n.a. & $55.2 \%$ & $52.3 \%$ \\
\hline
\end{tabular}

* Average per capita money incomes, monthly, Rubles. **Average per capita money, income, monthly, Rubles in 1998. *** In nominal Rubles.

n.a. indicates that the information is not available to us.

An interesting question is how poverty affects different demographic groups. The poverty ratio for different groups is presented in table 6. Men over sixty and woman over fifty-five who are not working are assumed to be 'retired'. Table 6 shows that the retired have a higher percentage of poverty incidence. Households with at least one child of 6 years or younger also have a higher percentage of poverty.

Table 6: Poverty ratios differentiated

\begin{tabular}{lcccc}
\hline & \multicolumn{2}{c}{ Wave 5 } & \multicolumn{2}{c}{ Wave 6 } \\
\hline Characteristic & LPL (04) & SFSPL (3) & LPL (04) & SFSPL (3) \\
\hline Retired & $88 \%$ & $89 \%$ & $92 \%$ & $96 \%$ \\
Non-Retired & $62 \%$ & $63 \%$ & $75 \%$ & $87 \%$ \\
$\begin{array}{l}\text { Household with Children with } \\
\text { age <=6 }\end{array}$ & $70 \%$ & $74 \%$ & $83 \%$ & $93 \%$ \\
$\begin{array}{l}\text { Household with Children with } \\
\text { age }>=7\end{array}$ & $69 \%$ & $69 \%$ & $79 \%$ & $89 \%$ \\
\hline
\end{tabular}




\section{Conclusions}

A discussion on different concepts and measurement of poverty is presented in this paper. Two concepts of poverty are presented, namely welfare, economic, poverty and well-being poverty. The last, is a broader concept that tries to capture satisfaction with life as a whole. In the Russian Federation for 1997 and 1998, the poverty incidence of welfare poverty is much larger than for well-being poverty.

Different approaches to the measurement of poverty are also presented in this paper. One, relative objective measures of poverty are discussed. This approach seems to be non-relevant as it gives only income distribution statistics describing relative income ratios but they are not related to absolute levels of poverty. The results for the Russian Federation yield incredibly low poverty ratios. Two, objective measures based on the "official" poverty line are discussed. The "official" poverty line is based on the work carried out by Popkins et al. (1996) who define poverty lines, minimum income level, based on a subsistence level of expenditures obtained as 1.3 times a subsistence food basket. In the paper, the "official" objective estimates are compared with two subjective measures, namely the Leyden Poverty Line (LPL), and the Subjective Financial Satisfaction Poverty Line (SFSPL). These subjective measures are more flexible as the "level" of satisfaction considered to be a "minimum" can be changed. When taking different satisfaction levels (e.g. 3 or 4 ) in a 11-level scale, into account the subjective measures can give rise to similar poverty ratios as those derived from the objective "official" poverty measurement.

Subjective measures show strong consistency, in other words, the outcomes from the LPL and the SFSPL are comparable. Furthermore, the results obtained by Ravallion and Lokshin (1999), using a subjective measure based on the Economic Ladder Question (ELQ), are also in line with our results derived from the Financial Satisfaction question.

Given such a multitude of poverty indicators the question arises: which of them should be preferred? This natural question, however, is easier asked than answered. The preferred measure of poverty depends on data availability and intuitive feelings. We would prefer to stick to one of the subjective measures because they are based on the respondents' feelings of income-poverty. Then SFS(3) and LPL(4) seem to be the most adequate. Besides, subjective measures are very flexible since the level below which an individual is considered poor can be easily changed. Thus, we can find poverty ratios using SFS(3) and also using SFS(4) or SFS(2). Besides the SFS and LPL, which measure income poverty, we have also presented a measure for well-being poverty. In our study well-being poverty, which is much lower than income poverty, is measured using a subjective question. Subjective well-being is a more complex phenomenon than financial satisfaction and thus more difficult to estimate and understand. Therefore the well-being poverty 
estimates for the Russian Federation have to be viewed with caution. Further research in this direction is needed.

The consistent results found for subjective measures, their flexibility and lower cost, and their importance in psychological matters, make us see a great future for such measures, both within the framework of poverty analysis and when the objective is to assess an individual's happiness. 


\section{References}

Argyle, M., 1999 Causes and correlates of happiness. In: Kahneman, D., Diener, E., and Schwarz (eds.). Well-Being: The Foundations of Hedonic Psychology. Russell Sage Foundation, New York. Chapter 18.

Atkinson, A.B., 1991. Comparing Poverty Rates Internationally: Lessons from Recent Studies in Developed Countries. World Bank Economic Review, 5: 32-21.

Blanchflower, D.G., and Oswald, A.J., 2000. Well-being over time in Britain and the USA. Presented at the Conference of Happiness, February, Oxford, UK.

Brickman, P., and Campbell, D.T., 1971. Hedonic relativism and planning the good society. Pp. 287-302. In: Apley, M.H. (ed.).Adaptation-level theory: A symposium. Academic Press, New York.

Cantril, H., 1965. The pattern of human concerns. Rutgers University Press. New Brunwick.

Clark, A. E., and Oswald, A. J., 1994. Unhappiness and unemployment. Economic Journal. 104: 648-659.

Deaton, A., and Muellbauer, J., 1986. On measuring child costs: With applications to poor countries. Journal of Political Economy, 94: 720-744.

DiTella , R., MacCulloch, R. J., and Oswald, A. J., 2000. Preferences over inflation and unemployment: Evidence from surveys of Happiness. American Economic Review, forthcoming.

Frijters, P., 1999. Explorations of welfare and well-being. Ph.D. Thesis N.196. Thela Thesis, the Netherlands.

Frijters, P. and van Praag,. B.M.S., 1998. The effects of climate on welfare and well-being in Russia. Climatic Change, 39:61-81.

Fuchs, V., 1967. Redefining poverty and redistributing income. Public Interest, summer: 88-95.

Frey, B.S., and Stutzer, A., 1999. Measuring preferences by subjective well-being. Journal of Institutional and Theoretical Economics. 155: 755-778.

Goedhart, Th., Halberstadt, V., Kapteyn, A., and van Praag, B.M.S., 1977. The poverty line: concept and measurement. Journal of Human Resources, 12: 503-520.

Hagenaars, A.J.M., 1986. The perception of poverty. North-Holland Publish Company, Amsterdam, the Netherlands.

Lokshin, M., and Popkin, B.M., 1999. The emerging underclass in the Russian Federation: Income dynamics, 1992-1996. Economic Development and Cultural Change. 47: 803-829.

Lokshin, M., and Ravallion, M., 2000. Welfare impacts of Russia's 1998 financial crisis and the response of the public safety net. World Bank MIMEO. 
Orshansky, M., 1965. Counting the poor: Another look at the poverty profile. Social Security Bulletin, 28: 3-29.

Oswald, A.J., 1997. Happiness and Economic Performance. Economic Journal. 107: 1815- 31

Plug, E.J.S., 1997. Leyden welfare and beyond. Ph.D. Thesis. Thesis Publishers Amsterdam, the Netherlands.

Plug, E.J.S., and Van Praag, B.M.S., 1995. Family equivalence scales with a narrow and broad welfare context. Journal of Income Distribution. 4: 171-186.

Popkin, B.M., Baturin, A.K., Mozhina, M., Mroz, T., Annu, S., Dmitrichev, I., Glinskaya, E., and Lokshin, M., 1996. The Russian Federation Subsistence Income Level: The development of regional food baskets and other methodological improvements. Report to the Russian federation and also the World Bank.

Ravallion, M., and Lokshin, M., 1999. Identifying Welfare Effects from Subjective Questions. World Bank, Washington D.C.

Rothbarth, E., 1943. Note on a method of determining equivalent income for families of different composition. In: Madge (ed.), Wartime pattern of saving and spending. Oxford U.P., Oxford.

Van Praag, B.M.S., 1971. The welfare function of income in Belgium: an empirical investigation. European Economic Review, 2: 337-369.

Van Praag, B.M.S., 1991. Ordinal and cardinal utility: an integration of the two dimensions of the welfare concept. Journal of Econometrics, 50: 69-89.

Van Praag, B.M.S., and Flik, R.J.,1992. Poverty lines and equivalence scales. A theoretical and empirical investigation. In Poverty Measurement for Economies in Transition in Eastern Europe, International Scientific Conference, Warsaw, 7-9 October, Polish Statistical Assosciation, Central Statistical Office.

Van Praag, B.M.S., and Frijters, P., 1999. The measurement of welfare and well-being; The Leyden approach. In: Kahneman, D., Diener, E., and Schwarz (eds.). Well-Being: The Foundations of Hedonic Psychology. Russell Sage Foundation, New York.

Van Praag, B.M.S., and Kapteyn, A.,1973. Further evidence on the Individual Welfare Function of Income: An empirical investigation in the Netherlands. European Economic Review, 4: 3362 .

Van Praag, B.M.S., and Plug, E.J.S., 1995a. New developments in the measurement of welfare and well-being. The Ragnar Frisch Centeniali, 1995 Oslo. Also Tinbergen Institute Discussion Paper 95-60. University of Amsterdam. 
Van Praag, B.M.S., and Plug, E.J.S., 1995b. The cost and benefits of children. Chapter 21. In: Ringen, S., and de Jong, P.R. (eds.). Fighting poverty: caring for children, parents, the elderly and health. Ashgate Publishing Ltd, Hants, UK.

Van Praag, B.M.S., Flik, R.J., and Stam, P.J.A.,1997. Poverty lines and equivalence scales: a theoretical and empirical evaluation. In: Keilman, N., Lyngstad, H.B., and Thomsen, I. (Eds.), Poverty and Economic Inequality in Industrialized Western Societies. Scandinavian UP, Oslo.

Van Praag, B.M.S., Hagenaars, A., and van Weeren, J., 1982. Poverty in Europe. Review of Income and Wealth, 28: 345-359.

Van Praag, B.M.S., Frijters, P., and Ferrer-i-Carbonell, A., 2000. A structural model of wellbeing: with an application to German Data. Tinbergen Institute Discussion paper TI 2000-053/3, the Netherlands.

Zohoori, N., Mroz, T.A., Popkin, B., Glinskaya, E., Lokshin, M., Mancini, D., Kozyreva, P., Kosolapov, M., and Sawfford, M., 1998. Monitoring the economics transition in the Russian Federation and its implications for the demographic crisis - the Russian Longitudinal Monitoring Survey. World Development. 26: 1977-1993. 
Table 3: Poverty lines for Wave 5 (1997) and Wave 6 (1998); In nominal rubles per month

\begin{tabular}{|c|c|c|c|c|c|c|c|c|c|c|c|c|c|c|c|}
\hline Famil & \multicolumn{2}{|c|}{ Half-mean } & \multicolumn{2}{|c|}{ Half-median } & \multicolumn{2}{|c|}{ SFS(3) } & \multicolumn{2}{|c|}{ LPL(4) } & \multicolumn{2}{|c|}{ SWB(4) } & \multicolumn{3}{|c|}{ From Popkin et al.* } & \multicolumn{2}{|c|}{ Official (GKS) } \\
\hline y Size & 1997 & 1998 & 1997 & 1998 & 1997 & 1998 & 1997 & 1998 & 1997 & 1998 & Char & 1997 & 1998 & 1997 & 1998 \\
\hline 1 & 277 & 272 & 209 & 217 & 638 & 1,281 & 634 & 857 & 351 & 1,195 & $\begin{array}{c}\text { Child } \\
0-6\end{array}$ & 501 & 833 & & \\
\hline 2 & 496 & 487 & 374 & 388 & 1,053 & 1,908 & 1,009 & 1,316 & 292 & 830 & $\begin{array}{c}\text { Child } \\
7-17\end{array}$ & 718 & 1,193 & & \\
\hline 3 & 679 & 666 & 512 & 532 & 1,412 & 2,409 & 1,324 & 1,690 & 309 & 733 & Male & 721 & 1,199 & & \\
\hline 4 & 839 & 824 & 633 & 658 & 1,740 & 2,842 & 1,605 & 2,019 & 369 & 705 & Fem. & 613 & 1,019 & & \\
\hline 5 & 994 & 976 & 750 & 779 & 2,045 & 3,231 & 1,864 & 2,318 & 480 & 706 & Pens. & 416 & 691 & & \\
\hline 6 & 1152 & 1132 & 869 & 903 & 2,333 & 3,588 & 2,106 & 2,594 & 672 & 725 & & & & & \\
\hline 7 & 1321 & 1297 & 997 & 1035 & 2,608 & 3,921 & 2,335 & 2,853 & 1,013 & 755 & & & & & \\
\hline & & & & & & & & & & & Avg. & 596 & 992 & 411 & 494 \\
\hline
\end{tabular}

Derived from Popkin et al. (1996) that offer 1993 estimates. The poverty lines have been translated into November 97 and November 98 prices. 
Table 4: Poverty ratios for Wave 5 (1997) and Wave 6 (1998) (in percentages)*

\begin{tabular}{|c|c|c|c|c|c|c|c|c|c|c|c|c|c|c|}
\hline \multirow[t]{2}{*}{$\begin{array}{l}\text { Fam. } \\
\text { Size }\end{array}$} & \multicolumn{2}{|c|}{ Half-mean } & \multicolumn{2}{|c|}{ Half-median } & \multicolumn{2}{|c|}{ SFS(3) } & \multicolumn{2}{|c|}{ LPL(4) } & \multicolumn{2}{|c|}{ SWB(4) } & \multicolumn{2}{|c|}{$\begin{array}{c}\text { Official } \\
\text { (Popkins) }\end{array}$} & \multicolumn{2}{|c|}{ Official (GKS) } \\
\hline & 1997 & 1998 & 1997 & 1998 & 1997 & 1998 & 1997 & 1998 & 1997 & 1998 & 1997 & 1998 & 1997 & 1998 \\
\hline 1 & 33 & 18 & 17 & 14 & 84 & 93 & 84 & 86 & 57 & 91 & 76 & 89 & 70 & 69 \\
\hline 2 & 23 & 20 & 19 & 14 & 73 & 86 & 73 & 77 & 16 & 51 & 71 & 84 & 49 & 58 \\
\hline 3 & 27 & 31 & 22 & 25 & 63 & 90 & 61 & 74 & 17 & 36 & 76 & 90 & 53 & 62 \\
\hline 4 & 34 & 35 & 27 & 25 & 64 & 91 & 63 & 79 & 20 & 31 & 88 & 95 & 52 & 57 \\
\hline 5 & 17 & 56 & 9 & 45 & 87 & 92 & 57 & 90 & 4 & 40 & 96 & 92 & 43 & 80 \\
\hline 6 & 67 & 48 & 50 & 43 & 100 & 86 & 83 & 86 & 50 & 43 & 100 & 90 & 67 & 76 \\
\hline 7 & 33 & 80 & 33 & 60 & 100 & 100 & 100 & 100 & 33 & 60 & 100 & 100 & 33 & 100 \\
\hline Total & 29.5 & 34.2 & 22.9 & 26.3 & 67.8 & 90.3 & 65.9 & 79.9 & 20.5 & 41.2 & 80.7 & 91.1 & 52.8 & 64 \\
\hline
\end{tabular}

* Number of people who live in a poor household 


\section{IZA Discussion Papers}

\section{No Author(s)}
171 C. Dustmann
F. Windmeijer
172
D. Card

173

174

175

176

O. Hübler

W. Meyer

177 B. R. Chiswick

G. Repetto

178 R. Euwals

M. Ward

179 E. Wasmer

P. Weil

180 T. K. Bauer

I. N. Gang

181 E. Wasmer

Y. Zenou

182 M. Fertig

C. M. Schmidt

183 M. Fertig

C. M. Schmidt

184 M. Corak

B. Gustafsson

T. Österberg

185 H. Bonin

K. F. Zimmermann
Titel

Area

Date

Wages and the Demand for Health - A Life Cycle

5

Analysis

Reforming the Financial Incentives of the Welfare

System

Timing, Togetherness and Time Windfalls

5

$7 / 00$

Does Money Illusion Matter? An Experimental Approach

Self-Employment and Earnings among HighSkilled Immigrants in the United States

Industrial Relations and the Wage Differentials

between Skilled and Unskilled Blue-Collar

Workers within Establishments: An Empirical

Analysis with Data of Manufacturing Firms

Immigrant Adjustment in Israel: Literacy and

Fluency in Hebrew and Earnings

The Renumeration of British Academics

5

$7 / 00$

The Macroeconomics of Labor and Credit Market Imperfections

Sibling Rivalry in Educational Attainment:

The German Case

Space, Search and Efficiency

$8 / 00$

$8 / 00$

Discretionary Measures of Active Labor Market

Policy: The German Employment Promotion Reform in Perspective

Aggregate-Level Migration Studies as a Tool for 1 Forecasting Future Migration Streams

$8 / 00$

Intergenerational Influences on the Receipt of

3

$8 / 00$

Unemployment Insurance in Canada and Sweden

The Post-Unification German Labor Market

4

$8 / 00$ 
A. S. Kalwij

The Myth of Worksharing

A. Zaidi

Is Unemployment Really Scarring? Effects of

The Determination of Wages and the Gender 
220 W. A. Cornelius

E. A. Marcelli

221

C. Grund

222 W.P.M. Vijverberg

223 M. Rosholm

M. Svarer

J. Schwarze

L. Modesto

J. P. Thomas

P. A. Puhani

227

L. Locher
G. Brunello

S. Comi

C. Lucifora
R. Coimbra
T. Lloyd-Braga
L. Modesto

230

L. Modesto

231

G. Saint-Paul

E. Bardasi

M. Francesconi

C. Dustmann

C. M. Schmidt
The Changing Profile of Mexican Migrants to the

Wages as Risk Compensation in Germany

On the Identification of Relative Wage Rigidity Cross-Section Data and Empirical Evidence for Poland in Transition

Immigration from the Eastern Block and the former Soviet Union to Israel: Who is coming when?

The College Wage Gap in 10 European

\section{Fluctuations} and Earnings: An Empirical Study for Portugal 

1969-95 the 1990s

244 S. M. Fuess, Jr. M. Millea

Pay and Productivity in a Corporatist Economy: 
